\title{
Professional Antigen Presenting Cells in Minor Salivary Glands in Sjögren's Syndrome: Potential Contribution to the Histopathological Diagnosis?
}

\author{
Saskia C.A. van Blokland, Annet F. Wierenga-Wolf, \\ Cornelia G. van Helden-Meeuwsen, Hemmo A. Drexhage, Herbert Hooijkaas, \\ Joop P. van de Merwe, and Marjan A. Versnel \\ Department of Immunology, Erasmus University Rotterdam and University Hospital Rotterdam-Dijkzigt, \\ Rotterdam, The Netherlands
}

\begin{abstract}
SUMMARY: Sjögren's syndrome is an autoimmune disease in which lymphocytic infiltrates develop in the salivary and lacrimal glands. We have shown that dendritic cells (DC) infiltrate the submandibular gland of the nonobese diabetic (NOD) mouse, a mouse model for Sjögren's syndrome, before lymphocytic infiltration, suggesting that these antigen-presenting cells (APC) may play a role in the initiation of Sjögren's syndrome. In later stages, DC and macrophages also form an important part of the infiltrate of the NOD sialoadenitis. To find out if DC and macrophages form part of the infiltrate in Sjögren's syndrome as well, and to determine whether they may be useful in the histopathological diagnosis of Sjögren's syndrome, we studied their presence in minor salivary glands (MSG) of patients with Sjögren's syndrome and patients with focal lymphocytic sialoadenitis (FLS), but without clinical or serological criteria of Sjögren's syndrome. Immunohistochemistry was applied, followed by semiquantitative analysis. DC and macrophages were present in all MSG; however, there were clear differences in marker expression between Sjögren's syndrome and FLS, on the one hand, and control tissue, on the other hand. CD1 ${ }^{+}$DC and RFD9 ${ }^{+}$macrophages were mainly observed in MSG in which a focal lymphocytic infiltrate was present. In fact, the diffuse presence of single CD1a ${ }^{+}$DC and $\mathrm{RFD9}^{+}$macrophages correlated closely with the presence of a focal lymphocytic infiltrate in the MSG. This indicates that these cells could be of help during the evaluation of a MSG. Because the detection of APC is technically less cumbersome than a focal score, this parameter may perhaps replace the focal score in the histopathological diagnosis of Sjögren's syndrome. This study therefore prompts further investigation focusing on the presence of $\mathrm{CD} \mathrm{a}^{+}$and RFD9 ${ }^{+}$cells in the MSG of a large cohort of patients. (Lab Invest 2000, 80:1935-1941).
\end{abstract}

\begin{abstract}
S jögren's syndrome is a chronic autoimmune dis$\int$ ease characterized by the presence of lymphocytic infiltrates in the salivary and lacrimal glands. The presence of these infiltrates is accompanied by decreased saliva and tear production. This is ultimately manifested by xerostomia and keratoconjunctivitis sicca (KCS) (Fox, 1995; Talal, 1990). Systemic manifestations, like arthritis, vasculitis, and serum autoantibodies directed to the ribonuclear proteins SS-A and SS-B, may be present as well (Aziz et al, 1992). A combination of immunologic, genetic, hormonal, and viral factors have been implicated in the pathogenesis of Sjögren's syndrome, but the initiating event of the autoimmune reaction is still not known (Aziz, et al, 1992; Fox, 1996a, 1996b).

Initiation of an (auto)immune response starts with the presentation of an antigen to antigen-specific $\mathrm{CD}^{+} \mathrm{T}$ cells by antigen-presenting cells (APC). APC include dendritic cells $(\mathrm{DC})$, macrophages, and $B$ cells (profes-
\end{abstract}

Received September 14, 2000.

Address reprint requests to: $D r$. Saskia C.A. van Blokland, Department of Immunology, Erasmus University Rotterdam, P.O. Box 1738, 3000 DR Rotterdam, The Netherlands. Fax: 31 10 4089456; E-mail: vanblokland@immu.fgg.eur.nl sional APC), but also nonprofessional APC, like epithelial cells. So far, with regard to the presence of leucocyte subsets in minor salivary glands (MSG) of patients with Sjögren's syndrome, attention has primarily been paid to the lymphocytic composition of the focal infiltrates (Adamson et al, 1983; Fox et al, 1982). Antigen-presenting cells have received little attention.

We have recently shown that, before the development of lymphocytic infiltrates, DC accumulate in the submandibular glands of nonobese diabetic (NOD) mice, a mouse model for Sjögren's syndrome (Humphreys-Beher, 1996; Humphreys-Beher et al, 1994). In the MRL/lpr mouse, another mouse model for Sjögren's syndrome (Hoffman et al, 1984), hardly any $\mathrm{DC}$ were present before the onset of sialoadenitis (van Blokland et al, 2000). This suggests that DC play an important role in the initiation of sialoadenitis in NOD mice, whereas in MRL/Ipr mice their role may be limited. In addition to the presence of DC in the early phase of sialoadenitis in NOD mice, DC as well as macrophages formed an important component of the focal infiltrates in a later phase of the autoimmune process.

The presence of DC and macrophages in the submandibular glands of NOD mice and the potential role 
of these cells in the initiation and perpetuation of the autoimmune reaction prompted us to study the presence of these cell types in the MSG of patients with Sjögren's syndrome. The MSG biopsy has an important role in establishing the diagnosis Sjögren's syndrome in all sets of criteria that are being used. However, evaluation of the focus score is a tedious procedure and requires the examination of more than one section by an experienced pathologist. Because histopathological involvement may be patchy, focal lymphocytic infiltrates of more than 50 mononuclear cells may be missed if only one section is used to examine the presence of a lymphocytic infiltrate. Furthermore, it has been estimated that the false positive rate of the minor salivary gland biopsy may be as high as $20 \%$, whereas inadequate scoring may be as high as $19 \%$ (Lee et al, 1998).

We therefore examined in a limited number of patients whether the presence of DC and macrophages in the MSG can be used as a scoring parameter for the histopathological diagnosis of Sjögren's syndrome, and whether the presence of these APC correlates with the presence of focal lymphocytic infiltrates. We not only used tissue from wellestablished Sjögren's syndrome patients, fulfilling the European criteria (ie, focal lymphocytic sialoadenitis along with symptoms and positive tests for dry eyes and dry mouth, and serum antibodies directed towards SS-A or SS-B), but also from patients with focal lymphocytic sialoadenitis only, without further clinical or serological criteria of Sjögren's syndrome (FLS). Patients without focal sialoadenitis and oral complaints, but with the clinical eye symptoms of Sjögren's syndrome, ie, keratoconjunctivitis sicca (KCS), were used as a negative disease control. Patients with complaints of Sjögren's syndrome, but lacking any clinical or pathological criteria for the disease, were also biopsied for diagnostic purposes. The tissues of these cases were used as negative controls. Briefly, the overall aim of this study was to investigate the presence of dendritic cells and macrophages in MSG and their potential contribution to the pathological practice.

\section{Results}

\section{Dendritic Cells in Minor Salivary Glands}

Three separate antibodies were used to study the presence of DC in MSG. L25 reacts with interdigitating cells in the thymus-dependent areas of peripheral lymphoid organs, and with B cells (Ishii et al, 1985). $\mathrm{CD}^{+} 3^{+}$cells represent mature DC (Zhou et al, 1992; Zhou and Tedder, 1995), whereas $\mathrm{CD}^{+} \mathrm{a}^{+} \mathrm{DC}$ represent DC that are positive for a molecule that plays a role in the presentation of lipid and glycolipid antigens (Moody et al, 1999; Sugita et al, 1999). Whereas L25 and $\mathrm{CD}_{83}{ }^{+} \mathrm{DC}$ were found in virtually all MSG, CD1 ${ }^{+}$ DC were specific for MSG in which a focal lymphocytic infiltrate was present.

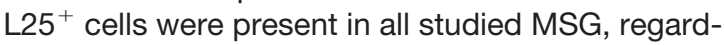
less of the presence of a lymphocytic infiltrate within the MSG (Figs. 1 and 2, $a$ and b). If there were focal lymphocytic infiltrates, the highest numbers of $\mathrm{L}^{2} 5^{+}$ cells were normally observed within these infiltrates. To discriminate between $\mathrm{DC}$ and $\mathrm{B}$ cells, the presence of $\mathrm{CD} 19^{+}$cells (B cells) within the MSG was also examined. Based on these stainings, we concluded that part, but not all, of the $\mathrm{L}_{2} 5^{+}$cells within the lymphocytic infiltrates were indeed $B$ cells. In the parenchyma of the MSG, $\mathrm{L}^{2} 5^{+}$cells were mainly DC, which was also suggested by the dendritic morphology of the cells.

$\mathrm{CD} 83^{+}$cells were present in the MSG of patients with Sjögren's syndrome or FLS, as well as in controls (Fig. 1). In MSG with a lymphocytic infiltrate, CD83 expression was found within parenchymatous tissue as well as in the lymphocytic infiltrate (Fig. 2d).

$\mathrm{CD} \mathrm{a}^{+} \mathrm{DC}$ were found in the MSG of all patients with Sjögren's syndrome and of the majority of patients with FLS (Fig. 1). Such cells were only present in $20 \%$ of the control patients, whereas they were absent in MSG of patients with KCS. In MSG in which a lymphocytic infiltrate was present, $\mathrm{CD}_{1} \mathrm{a}^{+} \mathrm{DC}$ oc-
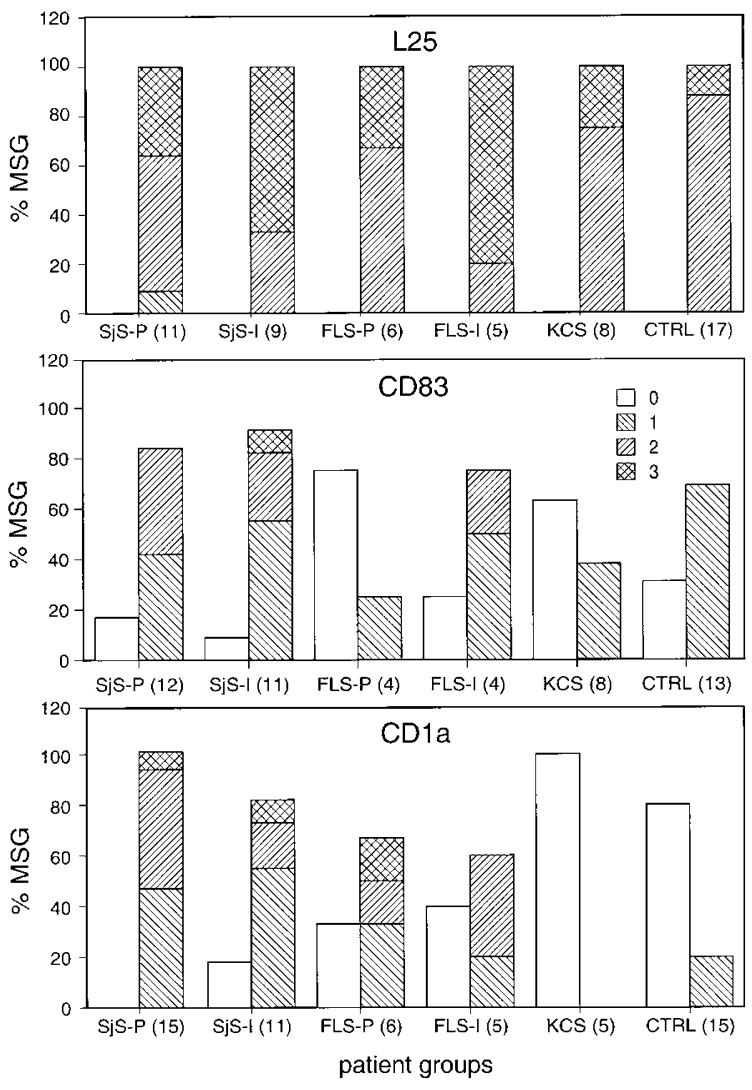

Figure 1.

Semiquantitative analysis of dendritic cell subsets in minor salivary glands (MSG) of patients with Sjögren's syndrome (SjS), focal lymphocytic sialoadenitis (FLS), and keratoconjunctivitis sicca (KCS), as well as in those of control subjects (CTRL). In MSG of patients with SjS and FLS, a distinction was made between positively staining cells located in the parenchyma $(P)$ and those in the lymphocytic infiltrate (I). The number of MSG studied is shown in parentheses for each condition. The following grading system was used: 0 , no positive cells; $1,1-5$ positive cells per $0.625 \mathrm{~mm}^{2} ; 2,6-30$ positive cells per $0.625 \mathrm{~mm}^{2} ; 3,30-100$ positive cells per $0.625 \mathrm{~mm}^{2}$. See Table 2 for the specificity of the monoclonal antibodies. 


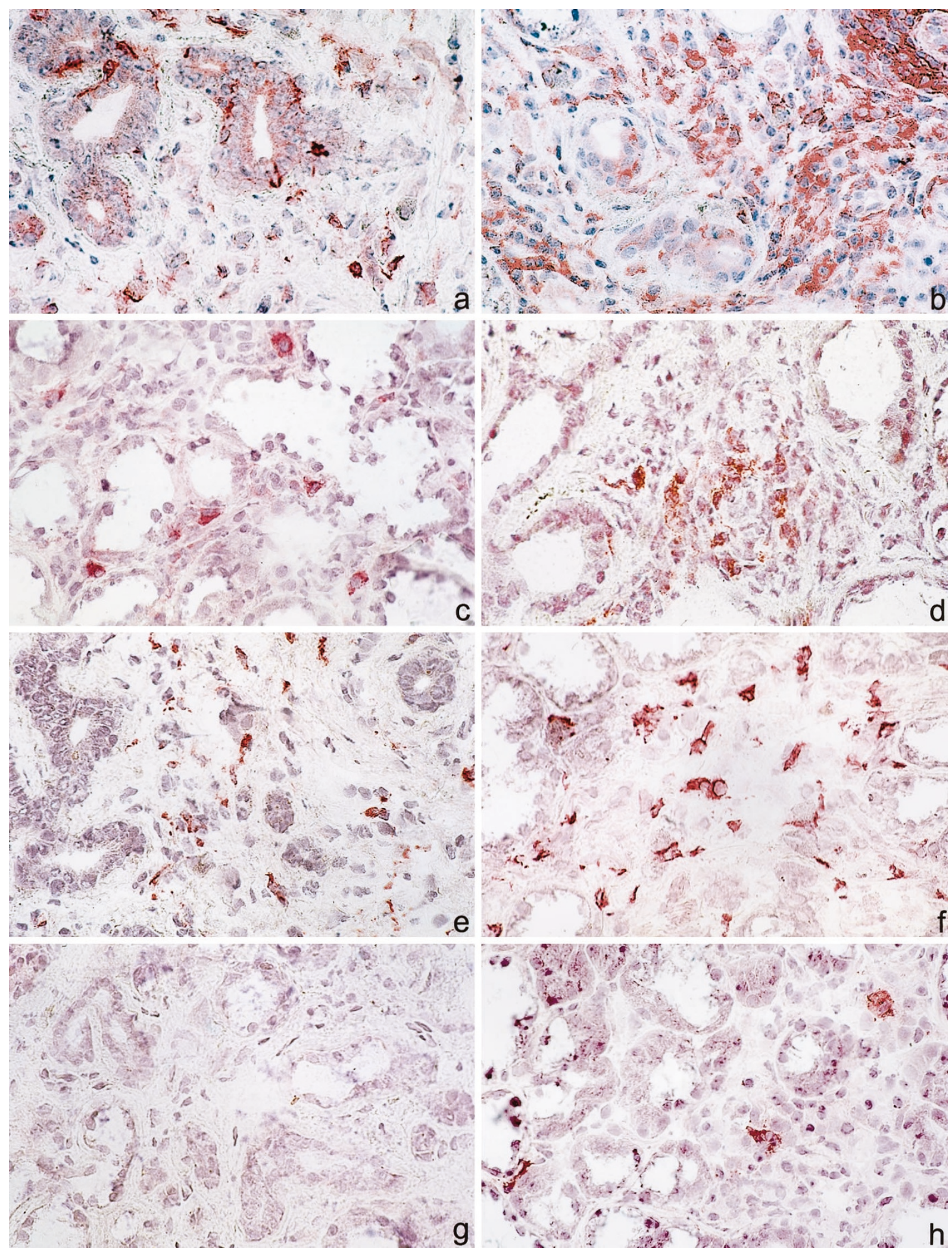

Figure 2.

Immunohistochemical detection of macrophages and dendritic cell subsets in MSG. $a$ and $b$, L25 $^{+}$dendritic cells present in a MSG of a control (a) and in that of a patient with FLS $(b) . c$ and $d,{\mathrm{CD} 1 \mathrm{a}^{+}}^{+}(c)$ and $\mathrm{CD}_{3}{ }^{+}(d)$ dendritic cells present in the parenchyma of a MSG of a patient with Sjögren's syndrome. $e$ and $f$, RFD7 ${ }^{+}$ macrophages present in a MSG of a control subject $(e)$, and in that of a patient with FLS $(f) . g$ and $h$, RFD ${ }^{+}$macrophages present in a MSG of a control subject $(g)$ and in that of a patient with Sjögren's syndrome $(h)$. Magnification, $\times 400$. 

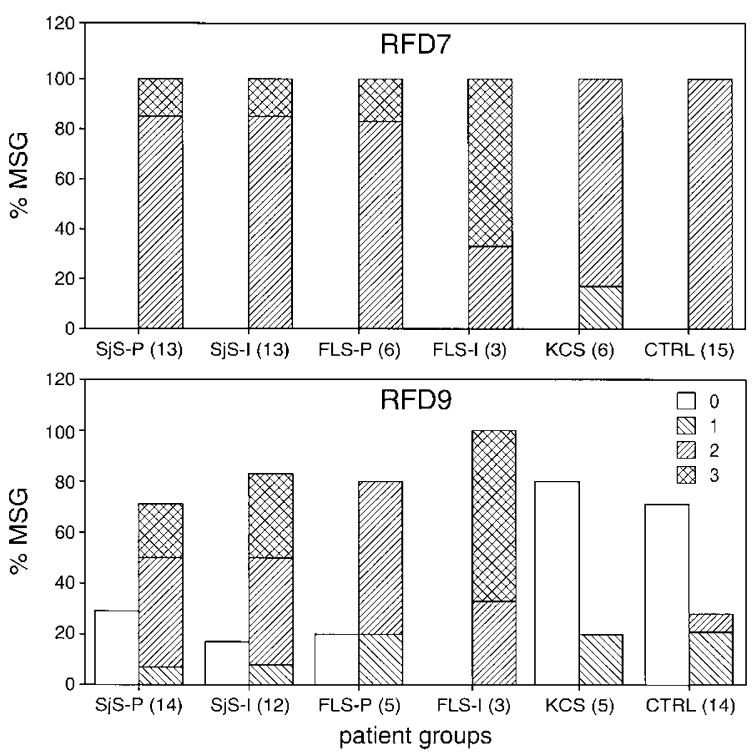

Figure 3.

Semiquantitative analysis of macrophage subsets in MSG of patients with SjS, FLS, and KCS, as well as in those of control subjects. In MSG of patients with SjS and FLS, a distinction was made between positively staining cells located in the parenchyma $(P)$ and those in the lymphocytic infiltrate (I). For details, see the legend for Figure 1 and Table 2.

curred both in the parenchyma of the gland (diffusely distributed) (Fig. 2c) and in the lymphocytic infiltrates.

\section{Macrophage Subsets in Minor Salivary Glands}

The MSG of patients with Sjögren's syndrome, FLS, $\mathrm{KCS}$, and controls were studied for the presence of $\mathrm{RFD7}^{+}$, mature tissue macrophages (Poulter et al, 1986), and RFD9+ macrophages, representing epithelioid cells (Poulter et al, 1986). RFD7 ${ }^{+}$macrophages were present in all MSG, regardless of the presence of a focal lymphocytic infiltrate (Figs. 2, e and f, and 3). In MSG in which a lymphocytic infiltrate was present, $\mathrm{RFD7}^{+}$macrophages were detected both within the infiltrate and scattered throughout the glandular parenchyma.

$\mathrm{RFD9}^{+}$cells were not so widely distributed. These macrophages were present in the parenchyma of the majority of patients with Sjögren's syndrome and FLS (71\% and $80 \%$, respectively), whereas they were largely absent in the control MSG (Figs. 2, $g$ and $h$, and 3). In MSG with a lymphocytic infiltrate, RFD9 ${ }^{+}$cells were present both within the lymphocytic infiltrate and in the parenchyma.
Correlation between the Presence of $\mathrm{CD}^{+} \mathrm{a}^{+}$Dendritic Cells and RFDg+ Macrophages and the Presence of Lymphocytic Infiltrates in MSG

$\mathrm{CD} \mathrm{a}^{+} \mathrm{DC}$ and $\mathrm{RFD9}^{+}$macrophages were mainly present diffusely distributed in MSG in which a lymphocytic infiltrate was also present. Because these cells were also detected in cases where the lymphocytic infiltrate was missed in the section used for the immunohistochemical staining, we examined whether the presence of these cell types in the parenchyma of the MSG correlates with the presence of a lymphocytic infiltrate.

Thirty-four MSG in which both markers were examined were divided into two groups: one group in which a positive focus score had been reported by the pathologist or was detected in this investigation in any section used for the immunohistochemical stainings, and another group in which lymphocytic infiltrates had never been observed, neither by the pathologist nor by us. The presence of $\mathrm{CD} \mathrm{a}^{+}$and RFD9 ${ }^{+}$cells in both patient groups is listed in Table 1.

The first observation that follows from Table 1 is that, in 6 of 19 MSG (32\%) in which we detected in our observations a positive focus score in any of the sections used for the immunohistochemical stainings, a negative focus score had been reported to the clinician by the pathologist. This underscores the notion that false negative scoring of the MSG biopsy is indeed a problem encountered by the pathologist when evaluating a MSG in routine procedures.

In 18 of 19 MSG (95\%) in which a positive focus score was detected, CD1a ${ }^{+}$DC were present. In 14 of these MSG, RFD9 ${ }^{+}$macrophages were also found. In total, $\mathrm{CD} \mathrm{a}^{+}$cells were found in 20 of 34 examined MSG, in $90 \%$ of which (18 of 20 ) a lymphocytic infiltrate was present, showing that the presence of $\mathrm{CD} \mathrm{a}^{+} \mathrm{DC}$ correlates significantly with the presence of a lymphocytic infiltrate. RFD9 ${ }^{+}$macrophages, though mainly present in MSG in which a lymphocytic infiltrate was present, were also found in 33\% (5 of 15) of MSG with a negative focus score.

\section{Discussion}

In this study the presence of DC and macrophages was examined in the MSG of patients with Sjögren's syndrome, related diseases, and controls. We found the presence of CD1 $\mathrm{a}^{+} \mathrm{DC}$ (and to a lesser extent that of $\mathrm{RFD9}^{+}$macrophages) to correlate with the presence of focal adenitis and hence to be rather specific for the histopathology accompanying Sjögren's syn-

Table 1. Correlation between the Presence of Focal Lymphocytic Infiltrates and the Presence of CD1a ${ }^{+}$and/or RFD9 ${ }^{+}$ Cells in Parenchyma of Minor Salivary Gland Biopsies

\begin{tabular}{lccccc}
\hline Focus score & $\begin{array}{c}\text { Number of } \\
\text { MSG }^{*}\end{array}$ & $\begin{array}{c}\mathrm{CD1a}^{+} \\
\mathrm{RFD9}^{+}\end{array}$ & $\begin{array}{l}\mathrm{CD}^{+} \mathrm{a}^{+} \\
\mathrm{RFD9}^{-}\end{array}$ & $\begin{array}{c}\mathrm{CD1a}^{-} \\
\text {RFD9 }^{+}\end{array}$ & $\begin{array}{c}\mathrm{CD1a}^{-} \\
\text {RFD9 }^{-}\end{array}$ \\
\hline Positive & $19(13)$ & $14 / 19$ & $4 / 19$ & $0 / 19$ & $1 / 19$ \\
Negative & $15(15)$ & $0 / 15$ & $2 / 15$ & $5 / 15$ & $8 / 15$ \\
\hline
\end{tabular}

* In parentheses, the number of MSG included in this part of the study that were scored positive or negative by the pathologist. 
Table 2. Monoclonal Antibodies Used in This Study

\begin{tabular}{lll}
\hline Antibody & Main specificity & \multicolumn{1}{c}{ Source } \\
\hline RFD7 & Macrophages & Dr. L.W. Poulter, London, UK \\
RFD9 & Macrophages & Dr. L.W. Poulter, London, UK \\
L25 & B cells, dendritic cells & Dr. T. Takami, Gifu, Japan \\
OKT6 & CD1a & Ortho Diagnostics, Raritan, NJ \\
HB15a & CD83 & Immunotech S.A., Marseille, France \\
\hline
\end{tabular}

drome. Because DC and macrophages are present, scattered throughout the glandular parenchyma, the detection of these cells in routine practice is likely to be easier for the pathologist than determination of the focal score, which needs more sections and levels of the gland to be evaluated. In our study, the percentage of MSG scored false negative in routine H\&E sections was shown to be as high as $32 \%$ when compared with the number of positive focal scores in sections used for immunohistochemistry. In over $80 \%$ of these latter MSG (5 out of 6$), \mathrm{CD} \mathrm{a}^{+}$DC were present.

Our study thus urges for a systematic, prospective, and well-controlled investigation of the presence of $\mathrm{CD} \mathrm{a}^{+}$and RFD9 ${ }^{+}$cells in a large cohort of patients to see if these markers can indeed be helpful in the histopathological diagnosis of Sjögren's syndrome and thus replace the tedious focal scoring. To further illustrate the necessity for critically viewing the outcome of the focal scoring, it has recently been described that smoking habits of patients might invalidate the use of the focus score in a MSG, because smoking lowers the focus score by reducing the accumulation of lymphocytes in the salivary glands (Manthorpe et al, 2000). Reduction of either the number or the size of lymphocytic infiltrates increases the problem of false negative MSG. Whether it affects infiltration by $\mathrm{CD}^{+} \mathrm{a}^{+} \mathrm{DC}$ and $\mathrm{RFD9}^{+}$macrophages needs further investigation.

Our study also shows that DC and macrophages are normal components of the MSG, albeit the cells are then almost exclusively CD1a and RFD9 negative (they are L25 and CD83 or RFD7 positive). RFD7 ${ }^{+}$ macrophages, detected in all MSG irrespective of the presence of a lymphocytic infiltrate, probably represent a resident macrophage population that is able to eliminate debris particles and microorganisms that invade the salivary gland (classical histiocytes). We found similar macrophages in submandibular glands of the NOD mouse, the MRL/lpr mouse, and control strains (unpublished observations).

DC are the most potent APC and are capable of activating naïve $\mathrm{T}$ lymphocytes (Stingl and Bergstresser, 1995). A role for these cells early in the process leading to the development of sialoadenitis can be envisaged. It can be imagined that $\mathrm{L} 25^{+} \mathrm{DC}$, possibly activated by events that may only occur in MSG of patients with Sjögren's syndrome or FLS, take up an autoantigen from the glandular tissue, travel to the draining lymph node, and activate antigen-specific $T$ lymphocytes. Activation and maturation of DC can be achieved by antigen uptake and processing or by exposure of DC to inflammatory agents (Austyn, 1996; Banchereau and Steinman, 1998).

The antigen CD1a, recognized by the antibody OKT6, is normally expressed on Langerhans cells within the epidermis of the skin (Murphy et al, 1981). In this study we described the presence of CD1a ${ }^{+}$cells in MSG in which a lymphocytic infiltrate has developed. Other inflammatory conditions in which CD1a ${ }^{+}$ cells have been detected include the lesions of patients with sarcoidosis. Perivascular areas of skin lesions, as well as granulomas within the lymph nodes and lungs of patients, were found to contain $\mathrm{CD} \mathrm{a}^{+}$ cells (Munro et al, 1987b). These results combined with ours suggest that the presence of $\mathrm{CD} \mathrm{a}^{+}$cells in the periphery may be due to a chronic inflammatory environment. With regard to up-regulation of CD1a in vitro, maturation of DC from CD14 ${ }^{+}$progenitors, induced by granulocyte-macrophage colonystimulating factor (GM-CSF) and tumor necrosis factor- $\alpha$ (TNF- $\alpha$ ), is accompanied by increased expression of CD1a (Cella et al, 1997). Interestingly, TNF- $\alpha$ mRNA and protein expression have been detected in the MSG of patients with Sjögren's syndrome, as well as in those of healthy volunteers. The highest levels were detected in patients with Sjögren's syndrome (Ajjan et al, 1998; Oxholm et al, 1992; Sun et al, 1998). The expression of CD1a on DC in MSG in which a lymphocytic infiltrate has developed may be the result of the production of the proinflammatory cytokine TNF- $\alpha$ by infiltrating cells. Alternatively, it may have occurred prior to the development of lymphocytic infiltrates, perhaps because of increased expression of TNF- $\alpha$ by epithelial cells, and may be an early event in the development of sialoadenitis.

The presence of RFD9 ${ }^{+}$macrophages, mainly in MSG with a lymphocytic infiltrate, is probably a reflection of the chronic inflammatory process characteristic of Sjögren's syndrome. RFD9 ${ }^{+}$macrophages have also been described in granulomas of patients with sarcoidosis, and although their precise role is unknown, it has been suggested that clustered RFD9 ${ }^{+}$ macrophages are involved in antigen processing and may contribute to the persistence of chronic inflammatory (autoimmune) reactions (Munro et al, 1987a). Whether RFD9 ${ }^{+}$macrophages are recruited to the MSG because of cytokine production by cells of the focal infiltrate or whether they mature from a precursor subset is not known.

In conclusion, in this study we have shown that professional APC are present in MSG, and a role for these cells in the development of autoimmune siaload- 
enitis can be envisaged. Furthermore, the presence of $\mathrm{CD} \mathrm{a}^{+} \mathrm{DC}$ and RFD9 ${ }^{+}$macrophages in MSG in which a lymphocytic infiltrate is present suggests the need for further investigation to see if these markers can be helpful in the histopathological diagnosis of Sjögren's syndrome.

\section{Materials and Methods}

\section{Patient and Controls}

Lip biopsies were obtained from various groups of patients. (a) Samples were taken from 15 patients (14 women and 1 man; ages 32 to 79 years) with Sjögren's syndrome according to the European Community Criteria (Vitali et al, 1993). In the serum of five of these patients, antinuclear antibodies or anti-SS-A or antiSS-B antibodies had been detected. All 15 patients also fulfilled the newly proposed European criteria for Sjögren's syndrome that require a positive focus score or antibodies to SS-A or SS-B in each patient (Vitali et al, 1997). (b) Samples were obtained from six patients (all women, ages 29 to 58 years) with focal lymphocytic sialoadenitis (FLS) only. Patients with FLS were characterized by the presence of focal lymphocytic infiltrates with a focus score equal to or greater than 1 in their MSG, but without keratoconjunctivitis sicca (KCS). Thus, these patients did not fulfill the clinical criteria to be diagnosed as having Sjögren's syndrome. (c) Samples were also obtained from eight patients (7 women, 1 man; ages 31 to 56 years) with KCS, without a completely developed Sjögren's syndrome. Patients with KCS were diagnosed on the basis of serious complaints of dry eyes, a positive Van Bijsterveld score, and an abnormal Schirmer test or break-up time. The outcome of the Schirmer test was considered abnormal if less than or equal to $5 \mathrm{~mm}$. The break-up time was considered abnormal if the outcome was lower than 11 seconds. (d) As control tissue, lip biopsies from 17 patients (15 women, 2 men; ages 34 to 76 years) were studied. These patients suffered from sicca complaints, but were negative in objective diagnostic tests for ocular and oral involvement. Neither antinuclear antibodies nor antiSS-A or anti-SS-B antibodies were detected in the serum of any of the control patients. Lip biopsies had been performed in all patients for routine diagnosis. Biopsies were either fixed in $10 \%$ buffered formalin or snap-frozen within 30 minutes in Tissue-tek embedding medium (Sakura Finetek, Torrance, California) using liquid nitrogen. Biopsies that were snap-frozen were stored at $-80^{\circ} \mathrm{C}$ and used for research purposes.

\section{Immunohistochemistry}

Frozen sections $(6 \mu \mathrm{m})$ from each biopsy were placed on poly-L-lysine-coated slides (Sigma Diagnostics, St Louis, Missouri) and fixed in acetone for 10 minutes at room temperature. Afterwards, the slides were rinsed in PBS (pH 7.8) for 5 minutes and incubated with 1\% bovine serum albumin in PBS for 10 minutes. Subsequently the slides were incubated with $10 \%$ normal rabbit serum (Dakopatts, Glostrup, Denmark) in PBS for 10 minutes, after which one of the monoclonal antibodies (MoAb) was applied (Table 2). L25 is a MoAb directed against $B$ cells and dendritic cells (Ishii et al, 1985) and was a generous gift of Dr. T. Takami (Department of Pathology, School of Medicine, Gifu University, Gifu, Japan). RFD7 and RFD9 are MoAb directed against macrophage subsets (Poulter et al, 1986), and these were kindly provided by Dr. L.W. Poulter (Department of Immunology, Royal Free Hospital, London, United Kingdom). The optimal dilutions were determined by titration. The slides were incubated with the primary antibody of interest for 60 minutes, rinsed in PBS for 10 minutes, and incubated for 30 minutes with rabbit antimouse $(\mathrm{R} \alpha \mathrm{M})$ immunoglobulin antiserum (175 $\mu \mathrm{g} / \mathrm{ml}$ ) (Dako A/S, Glostrup, Denmark). Subsequently, the sections were rinsed in PBS, incubated with alkaline phosphatase antialkaline phophatase (5 $\mu \mathrm{g} / \mathrm{ml})$ (DAKO A/S) for 30 minutes, rinsed in TRIS buffer ( $\mathrm{pH}$ 8.0), and incubated for 30 minutes with New Fuchsin substrate (Chroma, Stuttgart, Germany), which stained positive cells red. Finally, the slides were rinsed with water, counterstained with Mayer's hematoxylin (Merck Diagnostica, Darmstadt, Germany), and mounted in Kaiser's glycerol gelatin (Merck Diagnostica). Control staining was performed by substitution of the primary antibody with PBS and by incubation with an irrelevant monoclonal antibody of the same isotype and concentration. Stained sections were evaluated blindly by three independent persons (SvB, AW-W, and $\mathrm{CvH}-\mathrm{M})$, using a semiquantitative 0 to 3 scale (grade 0 , no positive cells; grade 1, 1-5 positive cells per $0.625 \mathrm{~mm}^{2}$; grade 2, 6-30 positive cells per $0.625 \mathrm{~mm}^{2}$; grade $3,30-100$ positive cells per $0.625 \mathrm{~mm}^{2}$ ). A distinction was made between cells staining positive located within a focal infiltrate and cells staining positive located in glandular tissue. In sections of MSG of patients with Sjögren's syndrome or FLS that were used to study one of the markers of interest, a lymphocytic infiltrate was not always present. In these cases however, the presence of a focal lymphocytic infiltrate was detected in other sections of these MSG.

\section{Acknowledgements}

We gratefully acknowledge Professor Dr. R. Benner for critical reading of the manuscript and Mr. T.M. van Os for photographic assistance and preparation of the figures (both with the Department of Immunology, Erasmus University Rotterdam). The pathologists of the Department of Pathology of the Erasmus University Rotterdam are gratefully acknowledged for evaluation of the focus score in the minor salivary glands. The personnel from the Department of Otorhinolaryngology and Professor Dr. C. de Baat from the Department of Special Dentistry and Oral Surgery, Academic Hospital Dijkzigt, are acknowledged for their collaboration. 


\section{References}

Adamson TC, Fox RI, Frisman DM, and Howell FV (1983). Immunohistologic analysis of lymphoid infiltrates in primary Sjögren's syndrome using monoclonal antibodies. J Immunol 130:203-208.

Ajjan RA, Mclntosh RS, Waterman EA, Watson PF, Franklin CD, Yeoman CM, and Weetman AP (1998). Analysis of the T-cell receptor Valpha repertoire and cytokine gene expression in Sjögren's syndrome. Br J Rheumatol 37:179-185.

Austyn JM (1996). New insights into the mobilization and phagocytic activity of dendritic cells [comment]. J Exp Med 183:1287-1292.

Aziz KE, Montanaro A, McCluskey PJ, and Wakefield D (1992). Sjögren's syndrome: Review with recent insights into immunopathogenesis. Aust N Z J Med 22:671-678.

Banchereau J and Steinman RM (1998). Dendritic cells and the control of immunity. Nature 392:245-252.

Cella M, Sallusto F, and Lanzavecchia A (1997). Origin, maturation and antigen presenting function of dendritic cells. Curr Opin Immunol 9:10-16.

Fox RI (1995). Sjögren's syndrome. Curr Opin Rheumatol 7:409-416.

Fox RI (1996a). Clinical features, pathogenesis, and treatment of Sjögren's syndrome. Curr Opin Rheumatol 8:438445.

Fox RI (1996b). Sjögren's syndrome: Immunobiology of exocrine gland dysfunction. Adv Dent Res 10:35-40.

Fox RI, Carstens SA, Fong S, Robinson CA, Howell F, and Vaughan JH (1982). Use of monoclonal antibodies to analyze peripheral blood and salivary gland lymphocyte subsets in Sjögren's syndrome. Arthritis Rheum 25:419-426.

Hoffman RW, Alspaugh MA, Waggie KS, Durham JB, and Walker SE (1984). Sjögren's syndrome in MRL/I and MRL/n mice. Arthritis Rheum 27:157-165.

Humphreys-Beher MG (1996). Animal models for autoimmune disease-associated xerostomia and xerophthalmia. Adv Dent Res 10:73-75.

Humphreys-Beher MG, Hu Y, Nakagawa Y, Wang PL, and Purushotham KR (1994). Utilization of the non-obese diabetic (NOD) mouse as an animal model for the study of secondary Sjögren's syndrome. Adv Exp Med Biol 350:631-636.

Ishii Y, Takami T, Kokai Y, Yuasa H, Fujimoto J, Takei T, and Kikuchi K (1985). A novel human B-lymphocyte antigen shared with lymphoid dendritic cells: Characterization by monoclonal antibody. Clin Exp Immunol 61:624-632.

Lee M, Rutka JA, Slomovic AR, McComb J, Bailey DJ, and Bookman AA (1998). Establishing guidelines for the role of minor salivary gland biopsy in clinical practice for Sjögren's syndrome. J Rheumatol 25:247-253.

Manthorpe R, Benoni C, Jacobsson L, Kirtava Z, Larsson A, Liedholm R, Nyhagen C, Tabery H, and Theander E (2000). Lower frequency of focal lip sialadenitis (focus score) in smoking patients. Can tobacco diminish the salivary gland involvement as judged by histological examination and antiSSA/Ro and anti-SSB/La antibodies in Sjögren's syndrome? Ann Rheum Dis 59: 54-60.

Moody DB, Besra GS, Wilson IA, and Porcelli SA (1999). The molecular basis of CD1-mediated presentation of lipid antigens. Immunol Rev 172:285-296.
Munro CS, Campbell DA, Collings LA, and Poulter LW (1987a). Monoclonal antibodies distinguish macrophages and epithelioid cells in sarcoidosis and leprosy. Clin Exp Immunol 68:282-287.

Munro CS, Campbell DA, Du Bois RM, Mitchell DN, Cole PJ, and Poulter LW (1987b). Dendritic cells in cutaneous, lymph node and pulmonary lesions of sarcoidosis. Scand J Immunol 25:461-467.

Murphy GF, Bhan AK, Sato S, Mihm MC, and Harrist TJ (1981). A new immunological marker for human Langerhans cells. N Engl J Med 304:791-792.

Oxholm P, Daniels TE, and Bendtzen K (1992). Cytokine expression in labial salivary glands from patients with primary Sjögren's syndrome. Autoimmunity 12:185-191.

Poulter LW, Campbell DA, Munro C, and Janossy G (1986). Discrimination of human macrophages and dendritic cells by means of monoclonal antibodies. Scand J Immunol 24:351357.

Stingl G and Bergstresser PR (1995). Dendritic cells: A major story unfolds. Immunol Today 16:330-333.

Sugita M, Grant EP, van Donselaar E, Hsu VW, Rogers RA, Peters PJ, and Brenner MB (1999). Separate pathways for antigen presentation by CD1 molecules. Immunity 11:743752.

Sun D, Emmert-Buck MR, and Fox PC (1998). Differential cytokine mRNA expression in human labial minor salivary glands in primary Sjögren's syndrome. Autoimmunity 28: 125-137.

Talal N (1990). Sjögren's syndrome. Curr Opin Immunol 2:622-624.

van Blokland SCA, van Helden-Meeuwsen CG, WierengaWolf AF, Drexhage HA, Hooijkaas H, van de Merwe JP, and Versnel MA (2000). Two different types of sialoadenitis in the NOD- and MRL/Ipr mouse models for Sjögren's syndrome: A differential role for dendritic cells in the initiation of sialoadenitis? Lab Invest 80:575-585.

Vitali C, Bombardieri S, Moutsopoulos HM, Balestrieri G, Bencivelli W, Bernstein RM, Bjerrum KB, Braga S, Coll J, and de Vita S (1993). Preliminary criteria for the classification of Sjögren's syndrome. Results of a prospective concerted action supported by the European Community. Arthritis Rheum 36:340-347.

Vitali C, Bombardieri S, and the European Study Group on Diagnostic Criteria for Sjögren's syndrome (1997). The European classification criteria for Sjögren's syndrome (SS): Proposal for modification of the rules for classification suggested by the analysis of the receiver operating characteristic (ROC) curve of the criteria performance. J Rheumatol 24 (suppl 50):38.

Zhou LJ, Schwarting R, Smith HM, and Tedder TF (1992). A novel cell-surface molecule expressed by human interdigitating reticulum cells, Langerhans cells, and activated lymphocytes is a new member of the Ig superfamily. J Immunol 149:735-742.

Zhou LJ and Tedder TF (1995). Human blood dendritic cells selectively express CD83, a member of the immunoglobulin superfamily. J Immunol 154:3821-3835. 